\title{
Free-Standing Interjections as Turn-Initial Pragmatic Markers-Examples from American Sitcom The Big Bang Theory
}

\author{
Anmin Mao \\ School of Foreign Languages, Yangtze University, Jingzhou, China \\ Email:mamiemao@qq.com
}

How to cite this paper: Mao, A.M. (2017) Free-Standing Interjections as Turn-Initial Pragmatic Markers-Examples from American Sitcom The Big Bang Theory. Open Access Library Journal, 4: e3809. https://doi.org/10.4236/oalib.1103809

Received: July 4, 2017

Accepted: August 8, 2017

Published: August 11, 2017

Copyright $\odot 2017$ by author and Open Access Library Inc.

This work is licensed under the Creative Commons Attribution International License (CC BY 4.0).

http://creativecommons.org/licenses/by/4.0/

\section{(c) (†) Open Access}

\begin{abstract}
Interjections in everyday conversations routinely function as pragmatic markers, especially when they are used to initiate utterances. In turn-initial position, the overall incidence of interjections is higher than non-interjectional pragmatic markers, as shown in the data from an American sitcom The Big Bang Theory. In the light of Fraser's "grammatical-pragmatic" approach to pragmatic markers, free-standing interjections are specifically discussed in the paper. Some instances of such "independent" interjections accord with what Fraser has defined as "basic markers", while others not. Also, it is found in the data that some interjections of this kind can serve as "parallel markers", or rather "vocative markers" and "speaker displeasure markers". Moreover, considering the large percentage that utterance-followed interjections account for in the frequency calculation of turn-initial interjections, it is believed that this type of "dependent" (i.e. not free-standing) interjections is also worthy of research, though has not been covered in detail in this paper.
\end{abstract}

\section{Subject Areas}

Linguistics

\section{Keywords}

Interjections, Pragmatic Markers, Turn-Initial Position, The Big Bang Theory

\section{Introduction}

Interjections in everyday conversations routinely function as pragmatic markers, especially when they are used to initiate utterances. Taking into consideration the close relationship among pragmatic marker, turn-initiator and interjections, 
this paper intends to make a corpus-based investigation of all these three aspects in one, namely, to investigate how interjections function both as both turninitiators and pragmatic markers.

Before the corpus-based analysis, some key concepts have to be clarified.

The theoretical framework for our interpretation of pragmatic markers in this paper is based on the research of Fraser [1] [2], who approaches pragmatic markers from solely "a grammatical-pragmatic perspective". He categorized pragmatic markers into general four types-basic pragmatic markers, commentary pragmatic markers, parallel markers, and finally, discourse markers-in line with four kinds of "potential direct messages" that a sentence may convey/be encodable by aspects of sentence meaning", namely, a basic/single message, commentary message, parallel message and discourse message. Pragmatic markers, in his words, are usually lexical expressions and do not contribute to the propositional content of the sentence but signal different types of message. Data collected from the five sitcom episodes (see 2. Data) would be analyzed within this framework, and some counter-examples found in the data would be put forth against certain points of view in this framework.

The relation between turn-initiator and pragmatic markers is also demonstrated in Norrick [3] that "pragmatic markers prototypically occur in turn-initial position". Similarly, Fraser [1] points out that "Fourthly, nearly all pragmatic markers may occur in sentence-initial position (though is one exception) and usually occur there." Based on the above statements, it is, thus, quite reasonable and workable to limit our focus on turn-initial pragmatic markers to exclude other periphery cases.

More specifically in the paper, interjections as turn-initial pragmatic markers are at issue. In addition to their division into primary and secondary, interjections are also classified according to their specific positions-namely, embedded, isolated, initial and final interjections. O'Connell, Kowal and Ageneau [4] have done such a research investigating the regular positional pattern of interjections. Their data are based on several English and German interviews (note that as a conversational genre, interview is, however, not as natural as conversations in sitcoms.). The results illustrate the flexibility of interjectional distribution (i.e. interjections are available for all the four positions) while initial positioned interjections share the second biggest percentage of all cases. Again in O'Connell and Kowal [5], a research on the Performance of Jane Austen's Pride and Prejudice also concludes that "interjections typically occur as turn-initial, as clauseinitial within a turn, and/or after a pause initiating an articulatory phrase,..." Similarly, the statistics (based on the American conversations in the Longman Spoken and Written English Corpus) collected by Norrick [6] also show that some of the commonest initial items are interjections, especially primary interjections. In view of these empirical researches, it is reasonable to hypothesize that turn initial-positioned interjections in American sitcoms would not be only a few but many in number for a data analysis. 


\section{Data}

The data used for analysis are natural conversations in American sitcom the Big Bang Theory (2009) Season 1 Episode 1-5, approximately 62920 seconds or 105 minutes with 14269 tokens in length.

Reasons for selecting this opera are as follows: Since this paper aims to investigate interjections as turn-initiators in two cases (free-standing or followed by utterances), thus by virtue of the oral (both medially and conceptually) property of interjections and the authenticity of conversations, the newly popular American sitcom the Big Bang Theory could be a good choice. Specific reasons are: for one thing, the Big Bang Theory (2009-) is temporally new avoiding the influencing factor of time on everyday language use; for another, unlike dialogues in interviews, films, plays or novels which are more constructed for artistic effect, conversations in sitcoms are supposed to be more natural, closer to real life, or rather the life of contemporary intellectual elites as shown in the Big Bang Theory. Last but not least, the original videos with subtitles and the officially published scripts are available online which is helpful for the data collection and analysis.

Still, as a case study, some variables should be taken into account by the author and readers when they extend the conclusions to general cases. In this paper, the data-based conclusion is an attempt to generalize some pragmatic features over interjections that function as turn-initial pragmatic markers in American natural conversations. Therefore, beforehand, some extraneous variables are pointed out here for readers' consideration in the further reading.

1) Gender; O'Connell and Kowal [5] empirically prove a dominance of interjections on the part of women. However, in the data most of the conversations are between male characters, only some are between male and female while seldom are between two females.

2) Age and social status; conversations are mostly among young intellectual elites.

3) Video genre; this TV opera is in itself sitcom (i.e. situation comedy), thus the storyline would be funny and more interjections are likely to occur compared with other cinematic types.

\section{Method}

English subtitles and official scripts of the five episodes (i.e. the Big Bang Theory (2009) Season 1 Episode 1-5) are cross-referenced when the data are collected. Also, for a better judgment of whether certain items are turn-initiators or not, original videos of the sitcom are meanwhile played, to the exclusion of occasions like monologue, think-aloud or songs.

Before the method specification, the concept of "interjection" has to be clarified in advance due to the consistent controversy over its definition. O'Connel, Kowal and Ageneau [4] adopt "a conservative operationalization of primary interjections" to get rid of standard discourse markers, filled pauses, YES and No 
as well as their variants, but include those common conventionalized non-content form. Norrick [7] disapproves of O'Connel et al. due to their lack of motivation, and instead opts for "a more inclusive definition of the class of interjections, following writers like Bloomfield (1933) and Nubling (2004)". Because of the topic relatedness between my research and that of Norrick [7], I follow his definition of interjections and also make a reference to his list of interjections (see [7], p868) when deciding on interjections in the conversational data.

By virtue of the above definition, a concise description of the method follows:

Firstly, I manually annotate the turn-initial pragmatic markers which are either free-standing or followed by utterances.

Secondly, data analysis is made: it involves making a list of expressions serving as turn initiators and then establishing their frequency in descending order on two sets of standard: 1) words of class; and 2) isolation (i.e. standing alone or followed by other utterances). To put it simply, for the purpose of investigating interjections, the collected items are first divided into two types: interjections and non-interjections (see Norrick, 2008, p. 868, Table 1, for reference); within these two classes, a sub-division is then made in consideration of whether the item(s) stand(s) alone or together with other utterances as a complete turn.

Thirdly, based on the numerical analysis, a general and then a more interjection-specific discussion are made successively in the next section.

\section{Results and Discussion}

Table 1 shows the frequency of occurrences of turn-initial pragmatic markers (both interjections and non-interjections) in the first five episodes of the Big Bang Theory, Season 1. Repeated combinations, such as "oh, oh,..." and "yeah, yeah,...", are counted as one element, to make it clear.

\subsection{Overall Discussion}

An overall impression of collected data (Table 1) is about the overwhelmingly larger number of interjections (276) as turn-initiators than non-interjections (81). Not only do interjections have a higher incidence but also they take more forms (i.e. there are 18 interjections while only nine non-interjectional items). This numerical feature is also true to interjectional and non-interjectional pragmatic markers that either stand alone (35:4) or are followed by utterances (251:77).

Actually, it is not difficult to find stretches where almost every single turn begins with interjectional pragmatic markers, rather than non-interjections or any constituent of grammatical unit, for instance the 14 turn excerpt in which eight turns start with interjections and no more than two with non-interjections.

LEONARD I think what Sheldon's trying to say is that Sagittarius wouldn't have been our first guess.

PENNY Oh, yeah, a lot of people think I'm a water sign. Okay, let's see, what else. Oh, I'm a vegetarian. No, except for fish and the occasional steak. 
Table 1. Turn-initial pragmatic markers in The Big Bang Theory (2009), Season 1, Episode 1-5 (interjectional and non-interjectional turn-initiators in the descending order of frequency of occurrences)

\begin{tabular}{|c|c|c|c|c|}
\hline Types & $\begin{array}{c}\text { Items } \\
\text { (turn-initial PMs) }\end{array}$ & Free-standing & $\begin{array}{l}\text { Initial in } \\
\text { turn }\end{array}$ & Total \\
\hline \multirow{10}{*}{$\begin{array}{c}\text { Primary } \\
\text { interjections }\end{array}$} & $\mathrm{OH}$ & 3 & 90 & 93 \\
\hline & $\mathrm{AH}$ & 2 & 11 & 13 \\
\hline & $\mathrm{UH}$ & & 10 & 10 \\
\hline & UM & & 7 & 7 \\
\hline & Wow & 1 & 4 & 5 \\
\hline & Нмм & & 2 & 2 \\
\hline & $\mathrm{MM}(\mathrm{M})$ & & 2 & 2 \\
\hline & SHH & & 2 & 2 \\
\hline & HuH & & 1 & 1 \\
\hline & BRRR. HEH. & 1 & & 1 \\
\hline \multirow{5}{*}{ * } & WHOO & & 1 & 1 \\
\hline & $\mathrm{OOH}$ & & 1 & 1 \\
\hline & Total & 7 & 131 & 138 \\
\hline & WELL & 1 & 53 & 54 \\
\hline & YEAH & 10 & 33 & 43 \\
\hline \multirow{4}{*}{$\begin{array}{l}\text { Secondary } \\
\text { interjections }\end{array}$} & OKAY & 4 & 14 & 18 \\
\hline & HEY & & 18 & 18 \\
\hline & GOD (GEE, GOOD LORD, HOLY SMOKES) & 3 & 1 & 4 \\
\hline & DAMN & & 1 & 1 \\
\hline \multirow[t]{6}{*}{$*$} & Total & 18 & 120 & 138 \\
\hline & Total of all interjections & 35 & 251 & 276 \\
\hline & so & 2 & 27 & 29 \\
\hline & (ALL) RIGHT & & 12 & 12 \\
\hline & REALLY & 2 & 7 & 9 \\
\hline & AND & & 9 & 9 \\
\hline \multirow[t]{6}{*}{ Non-interjections } & YOU KNOW & & 9 & 9 \\
\hline & BECAUSE & & 8 & 8 \\
\hline & BUT & & 2 & 2 \\
\hline & YOU KNOW WHAT & & 2 & 2 \\
\hline & ANYWAY...UM & & 1 & 1 \\
\hline & tal of all non-interjections & 4 & 77 & 81 \\
\hline
\end{tabular}

I love steak!

SHELDON Well, that's interesting. Leonard can't process corn.

LEONARD Ah, so, do you have some sort of a job?

PENNY $\underline{\text { Oh}}$, yeah. I'm a waitress at "The Cheesecake Factory".

LEONARD Oh, I love cheesecake. 
SHELDON You're lactose-intolerant.

LEONARD I don't eat it, I just think it's a good idea.

PENNY Oh, anyways, I'm also writing a screenplay. It's about this sensitive girl who comes to L.A. from Lincoln, Nebraska, to be an actress an winds up a waitress at "The Cheesecake Factory".

LEONARD So it's based on your life.

PENNY No, I'm from Omaha.

LEONARD Well, if that was movie, I would go see it.

PENNY I know, right? Okay, let's see, what else? Um, I guess that's about

it. That's the story of Penny.

LEONARD Well, it sounds wonderful.

\section{(Season 1, Episode 1)}

Still, Norrick [6] counts the corpora of the American conversations in the Longman Spoken and Written English Corpus and concludes that "somewhere around half (sometimes as few as around 30\% and sometimes as many as 65\%) of all new turns begin with something besides a constituent of a grammatical unit", and he further attributes such differences to the types of interaction and personal style. Thus, it is not proper to exaggerate the dominance of interjections as turn-initial pragmatic markers without take into account other individual factors.

\subsection{Free-Standing Interjections as Turn-Initial Pragmatic Marker}

Slight differences are found between primary and secondary interjections, whose total frequency of occurrences is unexpectedly equal, though it seems some secondary interjections (e.g. yeah) tend to be free-standing more often while some primary ones are more frequently used to elicit utterances than stay alone (e.g. $o h)$.

The following discussion mainly focuses on free-standing interjections only which serve in conversations as both turn-initiators and pragmatic marker.

Free-standing items form separately a complete turn. Since they stand alone, they are thus utterance initial by default. The third column of Table 1 entitled "Free-standing" demonstrates the statistics for free-standing interjections in the sitcom data. Note that the commonest free-standing interjections are secondary yeah (10), okay (4), God (3), and primary oh (3).

Within Fraser's framework of pragmatic markers (1996), most of the free-standing interjections fall into the category of "message idioms" (or to be exact, "pragmatic idioms"), which are one subset of "lexical basic markers". For these emotive words or phrases which stand alone and function as separate sentences, Fraser [1] makes further efforts to classify them in view of their semantic meanings which are said to "remains invariant throughout".

In the latter illustrations, I would argue for and when sufficiently supported by the data examples, against some of Fraser's points of view. The investigation starts with yeah, since it appears alone most frequently as an utterance according 
to the data.

In Fraser's words [1], “Yes! Yeah! Yup! Ok!” are conceptually used to express agreement. It is true for yeah(s) (three out of the ten cases) which occur in a declarative or exclamatory manner. They are used by addressers to signal agreement with a statement in the foregoing turn or form a direct positive response to a question, as in the following excerpt.

PENNY So you're like one of those "Beautiful Mind" genius guys.

SHELDON Yeah.

(Season 1, Episode 1)

The other seven yeah $(s)$, however, are interrogative, ending with a question mark. They, evidently, do not fit the conceptual meaning defined by Fraser [1]. In this case, "Yeah?" is equivalent to "Why?", “(So) what?" or "What's the matter?", applied in conversations to elicit speeches that the addresser means to say or is embarrassed to say. As illustrations, consider the three instances below:

LEONARD Penny, wait.

PENNY Yeah?

LEONARD Um... If you don't have any other plans, do you want to join us for Thai food and a Superman movie marathon?

(Season 1, Episode 2)

PENNY Leonard.

LEONARD $\underline{\text { Yeah? }}$

PENNY We're okay

(Season 1, Episode 2)

MARY You know how your daddy used to say that you can only fish for so long before you got to throw a stick of dynamite in the water?

SHELDON Yeah?

MARY Well, I'm done fishing. You put those on.

(Season 1, Episode 4)

Another exception to what Fraser [1] has defined as "invariant" conceptual meanings of free-standing interjections is found in the case of "Oh!", which is conceptually used to "express the receipt of new information". It might be true in some cases, but seems not in the following excerpt:

PENNY Hi.

LEONARD Oh.

PENNY What's going on?

LEONARD Uh. Here's the thing: [...]

PENNY Leonard.

LEONARD Yeah?

PENNY We're okay.

(Season 1, Episode 2)

The response "Oh." follows from a phatic expression "Hi.", which conveys lit- 
tle information but simply greetings, i.e. there exists no information to be received at all. Again, this example goes against Fraser's belief [1]. Free-standing "Oh." here is used as a polite reply to the foregoing greetings that may be to a little surprise of $L E O N A R D$, as in this example. It can be substituted for "Hi.", "Oh, hi/hey.", or "Oh, Penny [the greeter's name]" or else. For instance,

PENNY Oh, hey Leonard.

LEONARD Oh, hi.

PENNY So... how's it going?

LEONARD Pretty good.

(Season 1, Episode 5)

Actually, in natural conversations, free-standing oh is not common-the occurrences of entirely free-standing $o h$ in the collected data are no more than three times, but its combination with other interjections or content words (together as a complete utterance) turns out to be more popular-the frequency of such combinations amounts to 12 , four times more than single $o h(s)$. Specific examples include two cases:

1) $o h+$ another interjections, e.g. "Oh, (hi,) (Penny).", "Oh, yay/yeah. (no)", "Oh, boy", "Oh, what the hell", "Oh, God."; and

2) $o h+$ content words, e.g. "Oh, of course", "Oh, great", "Oh, no", "Oh, dear".

Consider a few examples:

PENNY Hmm, interesting.

SHELDON Isn't it?

PENNY No, I mean what you find enjoyable.

SHELDON Oh, boy.

PENNY What now?

SHELDON Well, there's some value to taking a multivitamin, but [...]

(Season 1, Episode 4)

MARY Did I pluck a nerve there?

HOWARD Oh, yeah.

MARY Okay. All right, everybody, it's time to eat. [...]

(Season 1, Episode 4)

Note that all these "independent" $o h$-combinations are still counted under the title "Initial in turn" in Table 1 . The mention of them here is only to call attention to such conversational phenomenon where the whole turn (initial interjection plus another interjection or certain expressions) could actually be treated as one "pragmatic idiom", as Fraser [1] called it. Similar interjectional combinations that stand alone as a complete turn in the data are listed below in Table 2.

Other free-standing primary interjections such as $a h$, wow, and brrr are generally in line with Fraser's definition as "basic markers", one type of pragmatic markers.

The cases of secondary interjections are relatively complex.

Secondary interjections like God together with its variants as Gee, good lord, 
Table 2. Interjectional combinations as free-standing turn-initiators in The Big Bang Theory (2009), Season 1, Episode 1-5.

\begin{tabular}{|c|c|c|}
\hline \multirow{2}{*}{ Initial interjection } & \multicolumn{2}{|c|}{ Combination with } \\
\hline & + interjection & + content expression \\
\hline oh & $\begin{array}{c}\text { Oh, hi, }\left(\text { Penny }{ }^{*}\right) \\
\text { Oh, yay/yeah. (no.) } \\
\text { Oh, boy. } \\
\text { Oh, God. } \\
\text { Oh, what the hell. }\end{array}$ & $\begin{array}{l}\text { Oh, great. } \\
\text { Oh, dear. } \\
\text { Oh, of course. } \\
\text { Oh, no. }\end{array}$ \\
\hline uh & Uh-huh. & Uh, yes \\
\hline $\mathrm{um}$ & & Um, Penny. \\
\hline $\mathrm{mm}$ & Mm...yeah. & \\
\hline well & $\begin{array}{l}\text { Well, ah, bye. } \\
\text { Well, yeah. }\end{array}$ & Well, you know. \\
\hline okay & & Okay, then. \\
\hline god & Gee...Ah... & \\
\hline damn & & Damn it, man. \\
\hline
\end{tabular}

* "Penny" is the name of the female character.

holy smokes belong to "vocative markers", one subclass of "parallel markers", "whose function is to signal an entire message in addition to the basic message" [1]. Take one example from the sitcom:

PENNY And what kind of doctor removes shoes from asses?

SHELDON Depending on the depth, that's either a proctologist or a general surgeon. Oh.

PENNY God!

LEONARD Okay, look, Penny. I think what you're feeling is perfectly valid and $[\ldots]$

(Season 1, Episode 4)

In the following excerpt, interjection damn plays the role of "speaker displeasure markers", another subclass of "parallel markers".

HOWARD Leonard, look out.

LEONARD Damn it, man.

SHELDON We're dying here. Goodbye, peasants.

(Season 1, Episode 3)

\section{Conclusions}

This paper attempts to investigate interjections functioning as turn-initial pragmatic markers, or to be exact free-standing interjections of this kind.

After a brief review concerning the close relations among interjection, pragmatic marker and turn-initiator, an empirical elaboration is made, first on the general comparison between interjectional and non-interjectional pragmatic markers in turn-initial position (4.1.), and later specifically on the free-standing 
turn-initial interjections as PMs (4.2.).

Data analysis indicates that, compared with non-interjectional turn-initial pragmatic marker, the overall incidence of interjections is higher. This data-based result is supportive of interjections' active participation into the system of everyday spoken language. Furthermore, as far as free-standing interjections are concerned, besides what Fraser [1] has defined as conceptual meanings for interjections of this kind ("message idioms") to realize, some examples in the data are found as opposed to Fraser's absolute classification. In addition to "lexical basic markers", "independent" interjections in turn-initial position could also serve as "parallel markers", or to be exact, "vocative markers" and sometimes "speaker displeasure markers", within the framework of Fraser [1] [2].

Turn-initial interjections which are followed by utterances, however, are not covered, in detail in the above discussion (Section 4.), though statistically, $90.94 \%$ of the total 276 interjections as turn-initial pragmatic markers in the sitcom conversations are followed by utterances. "Oh" and "well" appear to be the most popular primary and secondary interjections as initial pragmatic markers, with their respective frequency of occurrences as 90 and 53, far more beyond those free-standing cases. This fact implies that interjections in natural conversations are more often used to elicit utterances with more communicative information than merely used to express emotions or feelings.

In Fraser [2], he identifies three sources of discourse markers-conjunction, adverbs and prepositional phrases as well as a few idioms, to the exclusion of interjections. On the contrary, Norrick [7] illustrates interjections "with typical discourse marker functions of signaling contrast, elaboration transition and so on". In view of the above controversy and the finding results of this paper, further empirical researches in interjections as "dependent" (i.e. not free-standing) pragmatic marker are necessary and worthwhile, to make a clear look into the kaleidoscope of interjections.

\section{Acknowledgements}

No acknowledgments.

\section{References}

[1] Fraser, B. (1996) Pragmatic Markers. Pragmatics, 6, 167-190. https://doi.org/10.1075/prag.6.2.03fra

[2] Fraser, B. (1999) What Are Discourse Markers? Journal of Pragmatics, 31, 931-952. https://doi.org/10.1016/S0378-2166(98)00101-5

[3] Norrick, N.R. (2007) Discussion Article: Pragmatic Markers, Interjections and Discourse. Catalan Journal of Linguistics, 6, 159-168.

[4] O’Connell, D.C., Kowal, S. and Ageneau, C. (2005) Interjections in Interviews. Journal of Psycholinguistic Research, 34, 153-171. https://doi.org/10.1007/s10936-005-3636-3

[5] O'Connell, D.C. and Kowal, S. (2010) Interjections in the Performance of Jane Austen's Pride and Prejudice. Journal of Psycholinguistic Research, 39, 285-304. 
https://doi.org/10.1007/s10936-009-9138-y

[6] Norrick, N.R. (2009) Pragmatic Markers: Introduction. Journal of Pragmatics, 41, 863-865. https://doi.org/10.1016/j.pragma.2008.08.008

[7] Norrick, N.R. (2009) Interjections as Pragmatic Markers. Journal of Pragmatics, 41, 866-891. https://doi.org/10.1016/j.pragma.2008.08.005

Submit or recommend next manuscript to OALib Journal and we will provide best service for you:

- Publication frequency: Monthly

- 9 subject areas of science, technology and medicine

- Fair and rigorous peer-review system

- Fast publication process

- Article promotion in various social networking sites (LinkedIn, Facebook, Twitter, etc.)

- Maximum dissemination of your research work

Submit Your Paper Online: Click Here to Submit

Or Contact service@oalib.com 